\title{
Atividades Econômicas e Fisionomia das Vertentes no Maciço Residual de Uruburetama, Ceará, Brasil.
}

\author{
Economic Activities and Physiognomy of Strands in the Massif Residual Uruburetama, \\ Ceará, Brazil.
}

\author{
NASCIMENTO NETO, José N. do ${ }^{1}$; SOBRINHO ${ }^{1}$, José F. \\ josenelsonnascimento@gmail.com,
}

\begin{abstract}
Resumo
Este trabalho é um ensaio do projeto de mestrado acadêmico em Geografia da Universidade Estadual Vale do Acaraú-UVA. Objetivamos contribuir no planejamento ambiental do maciço residual de Uruburetama, no Ceará. Vincula que o relevo em questão proporcionou o processo de ocupação desencadeado por meio das cidades situada no maciço em questão associando a modificação de sua fisionomia por meio dos setores primário, secundário e terciários ao qual referenciamos refletir essa relação em um registro espaço-temporal. A metodologia consiste de uma revisão bibliográfica, atividades de campo, registro fotográfico e na elaboração do material cartográfico por meio do programa Qgis. Os resultados compreende a dinâmica dos setores econômicos que molda a fisionomia do relevo atento a essa realidade apresentamos como proposição uma elaboração de ações intervencionista que possam contribua no planejamento ambiental da área. Consideramos que o setor primário influência significativamente a fisionômica das vertentes sendo oportuno desenvolver um planejamento ambiental.
\end{abstract}

Palavras-chave: Maciço, Fisionomia e Setores Econômicos.

\begin{abstract}
This work is a test of academic master's project in Geography from the State University of Vale do AcaraúUVA. We aim to contribute to the environmental planning of the residual mass of Uruburetama in Ceará. Binds the relief in question provided the occupation process triggered by the cities located in the massif in question involving the modification of his face through the primary sector, secondary and tertiary to which we reference reflect this relationship in a space-time record. The methodology consists of a literature review, field activities, photographic records and the preparation of cartographic materials through Qgis program. The results include the dynamic economic sectors that molds the physiognomy of the eye relief to this reality presented as an elaboration proposition interventionist actions that can contribute to environmental planning of the area. We believe that the primary influence significantly sector physiognomic aspects of being useful to develop an environmental planning.
\end{abstract}

Keywords: Massive, Physiognomy and Economic Sectors.

\section{INTRODUÇÃO}

Este ensaio é um recorte do projeto de mestrado do programa de pós-graduação em Geografia da Universidade Estadual Vale do Acaraú-UVA. O projeto visa contribuir no planejamento ambiental do maciço residual de Uruburetama, no Ceará. O referido maciço tem sua história de ocupação associada ao uso desordenado dos seus recursos naturais. Assim, a exploração da sua natureza se dar em função dos meios naturais disponíveis, que gradativamente passou a ser alterada e descaracterizada no contexto de sua paisagem. Tais modificações, principalmente nas vertentes, acarretaram efeitos diferentes na economia, pois com a erosão do solo, ocorreu menor produção de alimentos e, consequentemente, repercutiu na economia do pequeno produtor.

\footnotetext{
${ }^{1}$ José Nelson do Nascimento Neto, Centro de Ciências Humanas, Universidade Estadual Vale do Acaraú-UVA, Sobral-CE, Brasil
}

${ }^{2}$ José Falcão Sobrinho, Centro de Ciências Humanas, Universidade Estadual Vale do Acaraú-UVA, Sobral-CE,Brail 
O maciço encontra-se localizado na região norte do estado do Ceará, compreende os municípios de Itapajé, Itapipoca, Irauçuba, Umirim, Uruburetama recorte administrativo politico da pesquisa, situam ainda a segunda e sexta região administrativa do Estado, ao passo que entendemos que esta delimitação, possibilita uma análise integrativa dos setores econômicos associados à realidade fisionômica da paisagem da área de estudo.

Descreve Silva (2007) que o maciço de Uruburetama é o que se encontra mais desconfigurado ambientalmente no Estado do Ceará se comparado com os outros que estão pontilhados sobre a superfície sertaneja.

A unidade ambiental de estudo, localiza-se na região semiárida do Nordeste Brasileiro, que se destaca por apresentar elementos de caráter social, econômico, cultural e ambiental diferente das demais regiões paisagística apresentada por Ab’Saber (2003).

Segundo dados levantados por Oliveira e Carrasco (2003, p, 114) a estrutura geomorfológica da área de estudo compreende $1.500 \mathrm{~km}^{2}$ e apresenta relevos tracejados perpendicularmente e com declividades acentuadas que se relaciona sistemicamente com o ambiente semiárido. Adequamos essa delimitação em $973,43 \mathrm{~km}^{2}$ em virtude das adaptações necessárias a realidade que o projeto visa atender, sendo necessário refletir sobre as atividades econômicas que marca processualmente a fisionomia das vertentes.

Conforme apresenta Ribeiro (1989, p, 32) a distribuição espacial das classes de atividade econômica sugere expressivo grau de correlação com o processo histórico da ocupação e povoamento de uma determinada região respectivamente em decorrência dos elementos naturais. Neste sentido, apresenta Araújo et al (2014, p, 19) a degradação das terras envolve a redução dos potenciais recursos renováveis por uma combinação de processos agindo sobre a terra.

A compreensão de sua localização refletida sobre uma base teórica sistêmica permite detalhar a realidade apoiada em uma metodologia condizente com o objeto.

Acreditando nesta afirmação, buscou-se refletir sobre a organização da paisagem que processualmente adapta ao longo do tempo-espaço a uma realidade, Bertrand (2005) ressalta que a paisagem é uma determinada porção do espaço, o resultado da combinação dinâmica, portanto instável, de elementos físicos, químicos e antrópicos que reagi dialeticamente uns sobre os outros, é em essência a realidade de um povo.

O que vislumbramos no andamento da pesquisa pauta-se em verificar que as atividades econômicas influenciam na descaracterização das paisagens que englobam as vertentes do presente maciço, tendo em óptica que o desenvolvimento econômico dos municípios é influenciado em função dos recursos naturais existentes. Em relação ao aspecto de ordem técnica buscamos pontuar as variáveis que intensificam a problemática em questão e partindo para um delineamento agrícola 
busca-se uma aplicação no modelo proposto por Ross (1992) da taxonomia do indicie de dissecação do relevo.

Se por um lado à sociedade tem a capacidade de interferir na natureza entendemos que os resultados de suas ações tendem a modificar o sistema natural em níveis e em ordens desconhecidas em âmbito global mas percebida em âmbito local. Colangelo (1995) aponta o conjunto de processos desencadeados a partir de intervenções humanas podem ser qualitativamente equivalentes àqueles ligados a dinâmica original dos sistemas de vertentes, uma vez que as leis naturais são sempre as mesmas e para a sociedade as leis são distintas em nível de organização já que determinados Estados formam suas bases jurídicas e administrativas.

Assim, os resultados estão pautados no contexto demográfico das cidades delimitada na pesquisa que situam na região de estudo, associados aos dados dos setores econômicos, que possibilita discutir a realidade social e natural da área, em razão da organização da paisagem e em função dos recursos naturais disponíveis.

\section{METODOLOGIA}

O trabalho concretizou-se por intermédio de uma séria de etapas fundamentais, partindo de uma lista de fundamentação teórica apropriada ao conteúdo, seguindo em etapa subsequente por uma tabulação de dados e confecção de gráficos por intermédio de programa Excel do ano de 2010.

Em etapas seguintes flui o planejamento sistematizado de visitas ao campo, com intuito de averiguar a influência das atividades econômicas, em etapas subsequentes tem se o conjunto de observações referente à fisionomia das vertentes questionando a realidade dos municípios em questão. Outro procedimento metodológico usado foi o registro fotográfico que serviu para constatação da realidade.

$\mathrm{Na}$ etapa de concretização emerge a síntese enquanto proposta de abordagem na realidade da natureza em questão, tendo em vista que a gestão do ambiente depende de uma necessidade de estudos técnico-operacionais e que devem ser deliberada via poder público com a participação da sociedade civil, carecendo de um envolvimento entre propostas, necessidades e ações vinculadas à realidade da escala da área da pesquisa.

Referenciando o Índice de Dissecação do Relevo proposto por Ross (1992) que tem princípios no projeto Radambrasil sendo modificado conforme a necessidade de escala, sendo, assim, os valores numéricos 52, 43, 33 e 24 que se pode verificar nos dados hipsometricos adiante diz respeito ao terceiro táxon proposto por ROSS (1992) que compreende as Unidades Morfológicas ou Padrões de Formas Semelhantes que estão contidas na Morfoescultura do relevo e 
são obtidos por meio de dados morfométricos relacionando a dimensão interfluvial média com o entalhamento médio dos vales e estão registrados nas colunas horizontais e verticais conforme se pode verificar no quadro da matriz dos índices de dissecação o relevo de Ross (1992).

$\mathrm{Na}$ etapa referente ao mapeamento da área foram utilizadas imagens de satélites do Landsat (8) do ano de 2014, disponibilizados pelo Instituto Nacional de Pesquisas Espaciais - INPE. Este serviu para a elaboração do mapa dos municípios e da declividade do maciço. $\mathrm{O}$ georeferenciamento foi realizado na projeção Universal Transversal de Mercator - UTM, com datum Sirgas 2000, zona 24 - S, os dados foram tratados a partir das técnicas de geoprocessamento através de Sistemas de Informações Geográficas - SIGsQgis.

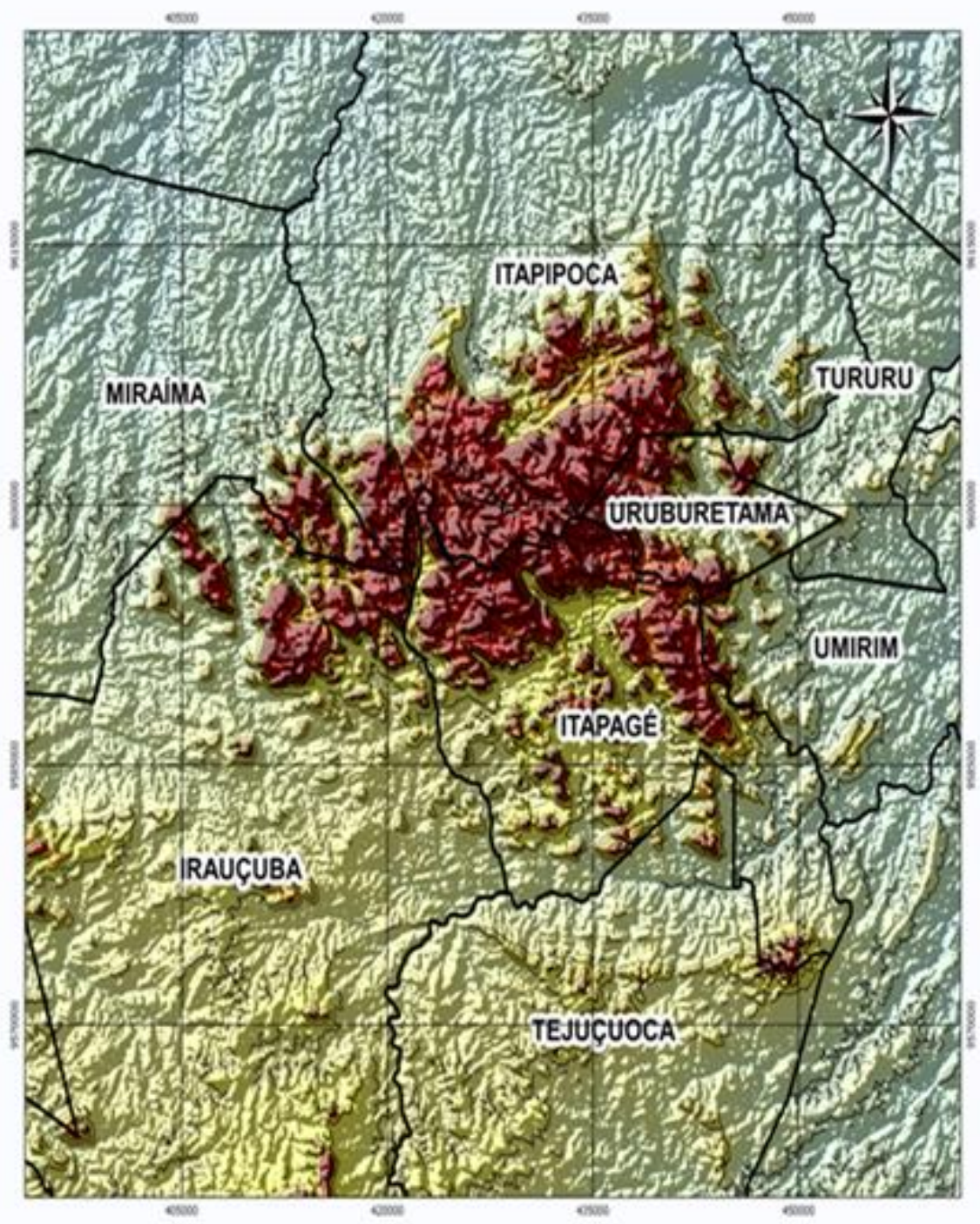

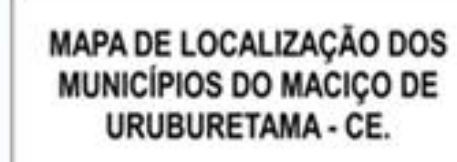
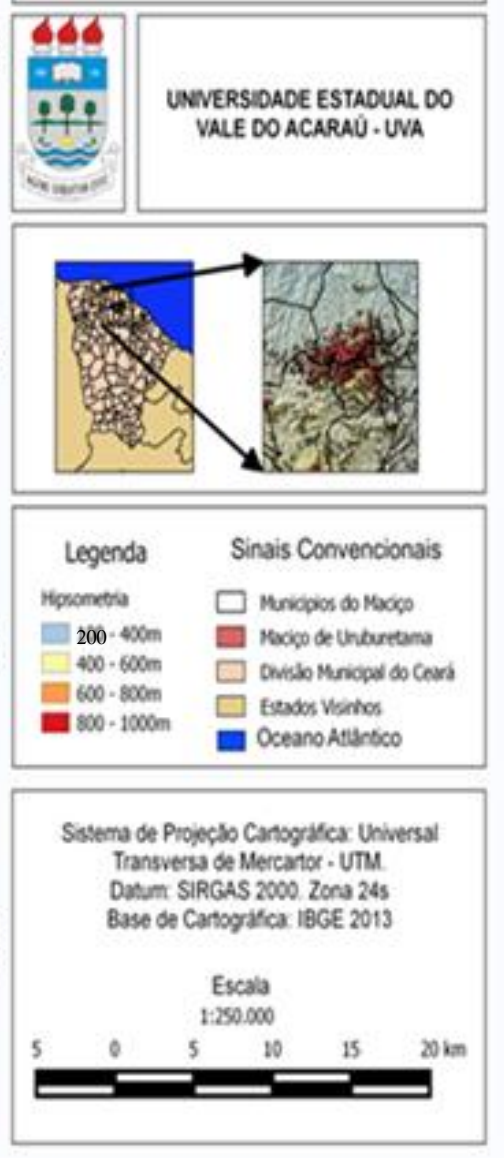

Titulo: Mapa de Localização da Área da Pesquisa

Fonte: NASCIMENTO NETO, J. N. (2016). 


\section{RESULTADOS E DISCUSSÂO}

O relevo é uma categoria de abstração, porém se materializa como o suporte das atividades das ações humanas. Suas formas influenciam as tomadas das decisões de muitas atividades, seja na engenharia, nos plantios no espaço rural ou ordenamento do espaço urbano. Materializa-se como algo perceptível, através das montanhas, das feições dunares ou ambientes desérticos. (FALCÃO SOBRINHO, 2007, p. 98). Neste sentido é pertinente o quadro natural da área em estudo abaixo.

Aspectos Naturais dos Municípios do Maciço, Ceará.

Municípios Temperatura Clima $\begin{aligned} & \text { Período Pluviosidade Bacia Vegetação Solos } \\ & \text { Chuvoso Média mm Hidrográfica }\end{aligned}$

\begin{tabular}{|c|c|c|c|c|c|c|}
\hline Uruburetama & $26 / 28^{\circ} \mathrm{C}$ & T. Q.S ${ }^{1}$ & Fev/Abr & 1274,5 & Curu & C.A.A ${ }^{1}$ \\
\hline Umirim & $26 / 28^{\circ} \mathrm{C}$ & T.Q.S.B ${ }^{2}$ & Jan/Mai & 127,5 & Curu & F.S.T.P A.B ${ }^{1} . L^{2} . P^{3}$ \\
\hline Irauçuba & $26 / 28^{\circ} \mathrm{C}$ & T.Q.S ${ }^{1}$ & Jan/Abr & 539,5 & Curu & C.A.A ${ }^{1} \quad$ B $^{1} \cdot L^{2} \cdot P^{3}$ \\
\hline Itapipoca & $26 / 28^{\circ} \mathrm{C}$ & T.Q.S.B ${ }^{2}$ & Jan/Mai & 1130,4 & Litoral & $\mathrm{L}^{2} . \mathrm{P} . \mathrm{P}^{3}$ \\
\hline Itapajé & $26 / 28^{\circ} \mathrm{C}$ & T.Q.S ${ }^{1}$ & $\mathrm{Jan} / \mathrm{Abr}$ & 800,3 & Curu & $\mathrm{B}^{1} \cdot \mathrm{L}^{2} \cdot \mathrm{P}^{3}$ \\
\hline
\end{tabular}

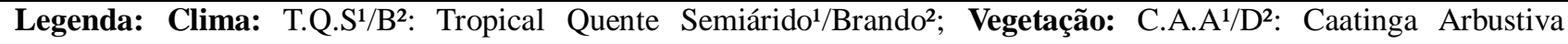
Aberta1/Densa ${ }^{2}$ e Floresta Subperenifolia Tropical Pluvial. Solos: $\underline{A}$ : Aluviais; $\underline{B^{1}:}$ Bruno Não-Cálcio; $\underline{L^{2}:}$ Litólicos; $\underline{P^{3}}$ : Podzólico Vermelho-Amarelo: $\underline{P}$ : Planossolos.

Tabela 01: Aspecto Naturais dos Municípios da Área da Pesquisa.

Fonte: Adaptado do IPECE (2015), Organizado por NASCIMENTO NETO, J. N. (2016).

A natureza associada aos elementos da paisagem possibilita imaginar a dinâmica do contexto ambiental e social da pesquisa considera Falcão Sobrinho (2009, p, 154) que os maciços residuais úmidos, são áreas que quebram a monotonia no cenário da paisagem da superfície sertaneja, em formas de maciços cristalinos.

Diante do contexto anterior aplicando-se a um mapeamento cartográfico na área da pesquisa tem-se por meio de dados hipsómetrico informações fundamentais que possuem uma aplicação na proposta dos índices de dissecação do relevo, seguindo os modelos apresentado por Ross (1992). Conferiu-se a sistematização dos dados e obteve-se os seguintes valores de intervalos sendo eles, 200-400m, 400-600m, 600-800m e 800-1000m com intervalos de 200m aplicados à matriz dos índices de dissecação do relevo proposta por Ross (1992) identificam-se os seguintes intervalos numéricos são eles 52, 43, 33 e 24 que representa os padrões fisionômicos da drenagem que molda as vertentes do maciço de Uruburetama. 
Neste aspecto, o valor numérico 52 adequa-se a classe de grande dimensão interfluvial apresentando ainda grau de entalhamento muito forte estando situada entre as vertentes a barlavento e sotavento, no valor de numérico 43 compreende a classe de média dimensão interfluvial sendo o grau de entalhamento corresponde a forte. Seguindo com o valor numérico 33 que corresponde à média dimensão interfluvial e médio no grau de entalhamento e finalizando com muito pequena a dimensão interfluvial é fraco o grau de entalhamento dos vales.

Dentro do ambiente geomorfológico isso referencia:

a) Vertente a Sotavento e Barlavento - Classe Muito Forte $\mathrm{N}^{\circ} 52$

b) Unidades de Vertentes Sub-úmidas e Secas - Classe Forte $N^{\circ} 43$

c) Unidade de Vertente Sub-úmidas - Classe Média Nº 33

d) Unidade de Pediplanação - Classe Fraca $N^{\circ} 24$

Entendemos que as atividades econômicas estão associadas aos recursos naturais disponíveis na natureza, em que, optamos por analisar os dados econômicos dos municípios da pesquisa. Assim, esses dados são apresentados em forma de gráficos abaixo sendo o registro temporal que compreendidos os anos de 2004 a 2014. Ainda elencamos que esses dados econômicos podem expressar a dinâmica paisagística que permite planejar o aspecto em nível de zoneamento econômico ecológico sendo cabível aqui considerar o planejamento agrícola atrelado ao planejamento ambiental de modo global.

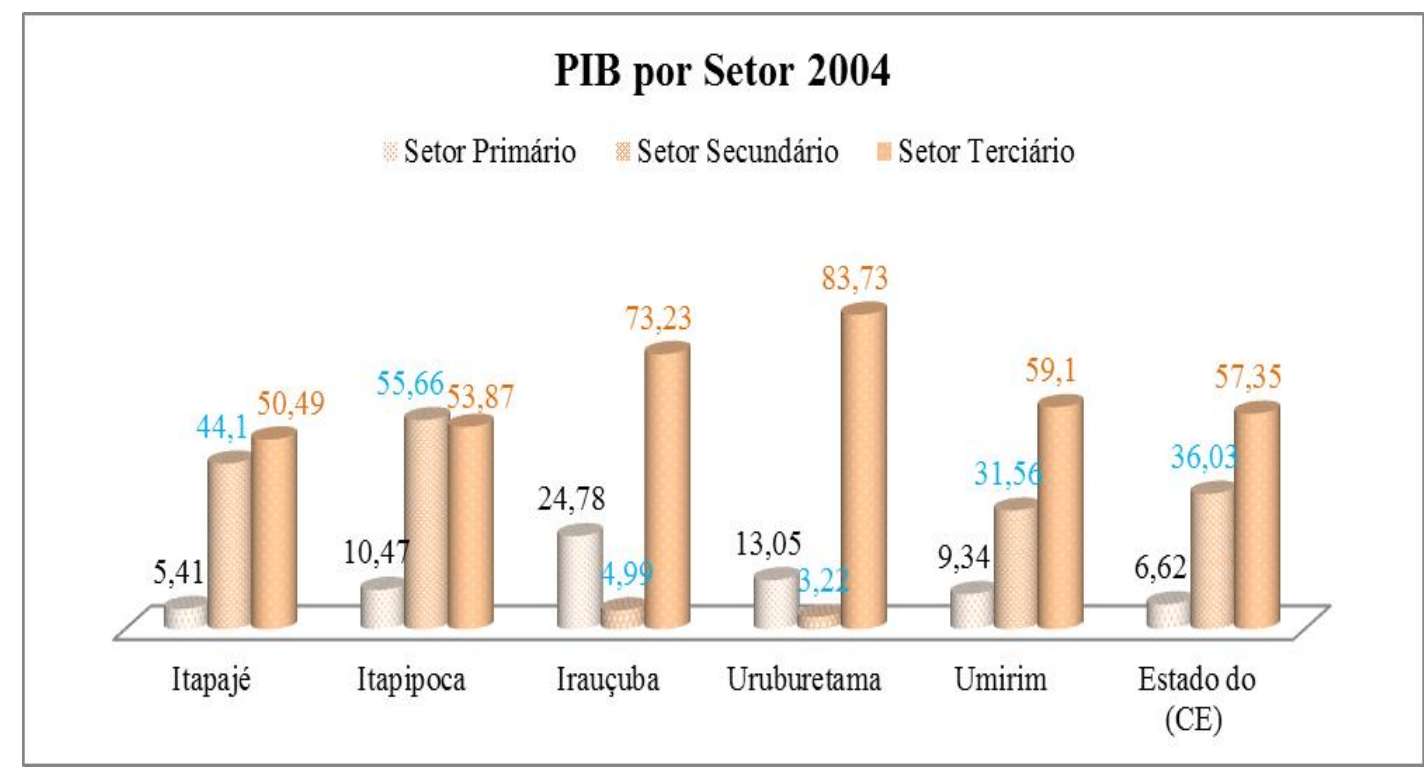

Gráfico 01: Aspecto econômico dos municípios do maciço residual de Uruburetama, CE. Fonte: Adaptada do IPECE (2014). Organizado por NASCIMENTO NETO, Jose Nelson. (2016).

Nos dados referentes à economia que permeia os setores primário, secundário e terciário observa-se que o setor primário está intimamente ligado ao uso, agravando-se pela exploração intensa pela agricultura em pontos com uso sucessivo e neste contexto, os dados do Estado do Ceará 
representa uma média de 6,62\% no ano de 2004. Sendo que apenas o município de Itapajé representou dados abaixo da média com $5,41 \%$ o que nos inferi confirmar que existe um uso acentuado desse setor pelos municípios o que configura uma descaracterização da paisagem representada pelas figuras B) e C) como se verifica abaixo.

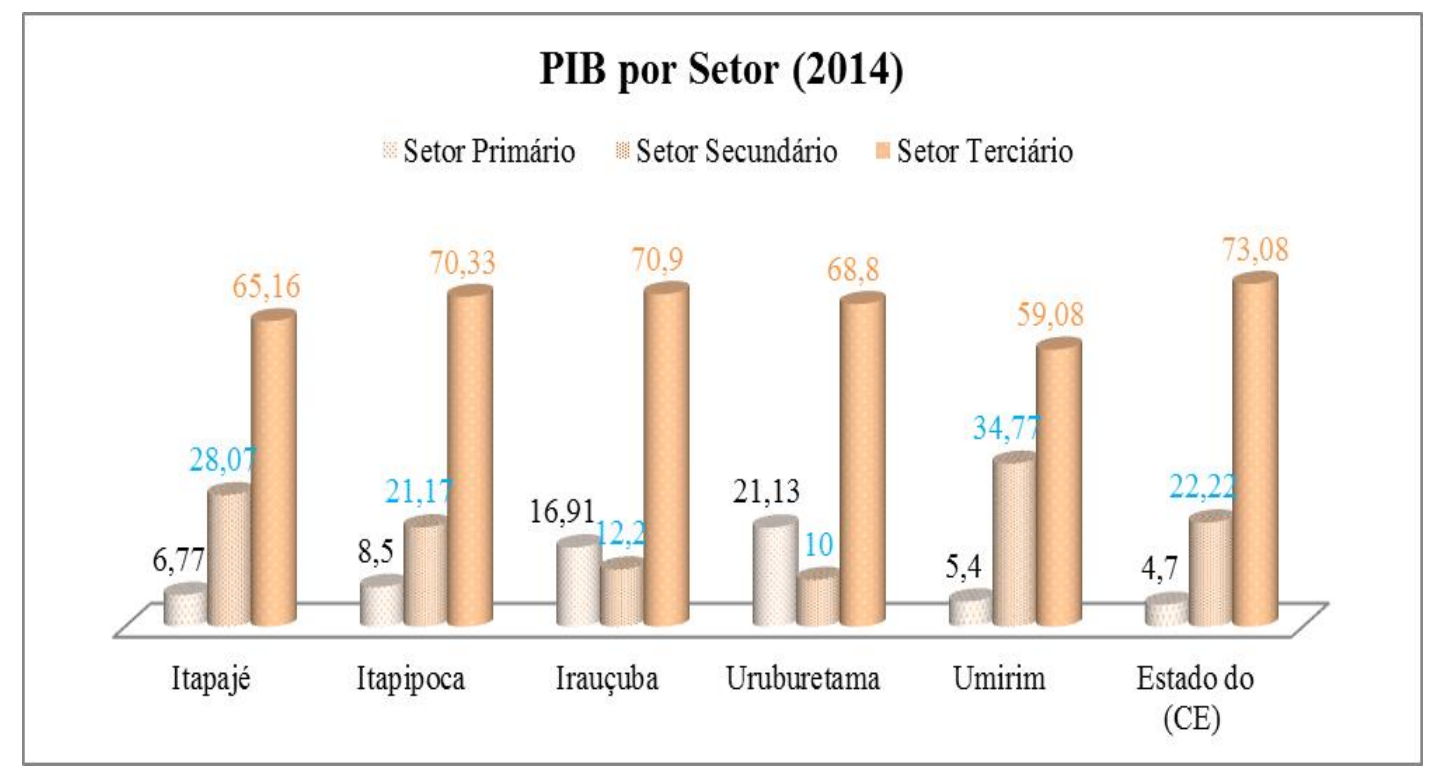

Gráfico 02: Aspecto econômico dos municípios do maciço residual de Uruburetama, CE. Fonte: Adaptado do IPECE (2014). Organizado por NASCIMENTO NETO, J. N. (2016).

Em relação ao ano observado o setor primário tem-se que todos os municípios passaram da média anual do Estado do Ceará que fechou em 4,7\% referente ao ano de 2014 e girando entre 5,4\% e 16,91\% entre os municípios em observação o que ainda permite afirmar que o setor primário é exerce uma dinâmica fundamental na economia da área da pesquisa por meio do uso dos recursos naturais.

No setor secundário observou-se que três municípios apresentam dados inferiores ao do Estado sendo eles Itapipoca com registrou 21,17\%, sendo seguido por Irauçuba com 12,20\% e Umirim com $10 \%$ estando abaixo da média do Estado do Ceará que é de 22,22\% o que evidencia o papel da indústria atuando de modo gradativo na economia da área da pesquisa sendo responsável juntamente com o setor primário por quase $50 \%$ do perfil econômico dos municípios observados dinamizando o mercado interno.

Para o setor terciário observou-se que nenhum dos municípios atingiu a média do Estado do Ceará que fechou em 73,08\% no ano de 2014 o que exemplifica afirmar que o setor de serviços no Estado é responsável por mais de $50 \%$ de toda a economia. E relacionando com os municípios observados constata-se a dependência econômica por este setor e abrindo discussões sobre a distribuição de emprego e renda em escala municipal já que constatou-se uma variação de 59,08\% a 70,33\% na dinâmica da área da pesquisa. 
Considerando os dados analisados vislumbramos possibilidade de direcionar uma análise empírica da paisagem por intermédio do registro fotográfico que apresentam as vertentes da unidade ambiental permitindo sistematizar e associar proposta de uso racional dos recursos naturais conforme proposta de planejamento ambiental que segue na Tabela de numero 02. A seguir é apresentado um mosaico com figuras sequenciadas em a), b), c) e d) sobre as vertentes da área da pesquisa.
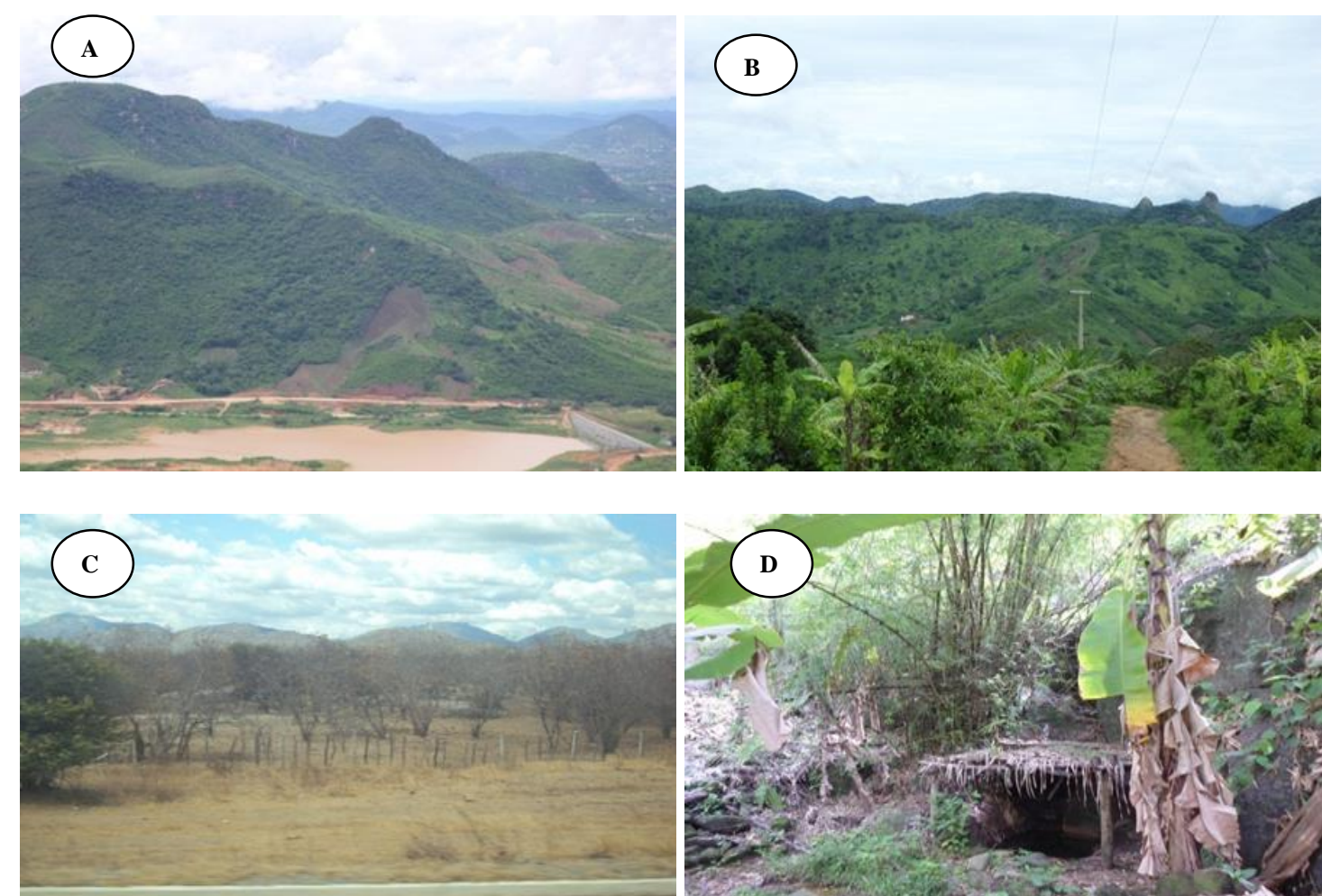

Figura 01: Mosaico das Vertentes do Maciço, A) Vertente com Solo Exposto; B) Plantio da Bananeira nas Vertentes Úmidas; C) Vertentes Secas do Maciço e Caatinga Arbustiva Aberta e D) Nascente Degradada. Fonte: NASCIMENTO NETO, J. N. (2014).

As registro fotográficos expressam na figura " $\mathrm{A}$ " o desgaste da cobertura vegetal em uma vertente sub-úmida associada a exposição do solo, na figura "B" temos o registro atividades agrícolas com destaque a monocultura da banana entre as vertentes do maciço, na figura " $\mathrm{C}$ " temos a aridez da vertente seca no setor baixo do maciço e na figura " $\mathrm{D}$ " temos respectivamente uma nascente com proteção rustica circulada por atividades agrícolas diversas como a bananeira.

Acreditamos que um planejamento ambiental possibilita atingir um desenvolvimento sustentável em face da descaracterização atual, porém, se faz necessário atingir uma série de etapas e propostas que qualificamos com ações de intervenção para alcançar progressivamente, processual e ordinalmente um equilíbrio da natureza em questão. 


\begin{tabular}{c|c}
\hline \multicolumn{2}{|c}{ Ações Intervencionistas } \\
\hline Proposta 01 & $\begin{array}{c}\text { Assegurar a assistência técnica comunitária ao setor } \\
\text { agrícola em âmbito municipal. }\end{array}$ \\
\hline Proposta 02 & $\begin{array}{c}\text { Informar a sociedade civil a importância da preservação } \\
\text { dos recursos naturais. }\end{array}$ \\
\hline Proposta 03 & $\begin{array}{c}\text { Elaborar um plano de conservação e preservação dos } \\
\text { recursos naturais do maciço. }\end{array}$ \\
\hline Proposta 04 & $\begin{array}{c}\text { Fiscalizar a nível municipal o meio ambiente buscando } \\
\text { integrar a nível estadual as operações de fiscalização. }\end{array}$ \\
\hline Proposta 05 & $\begin{array}{c}\text { Desenvolver um planejamento setorizado entre as } \\
\text { secretárias municipais visando atingir a preservação e } \\
\text { proteção da natureza. }\end{array}$ \\
\hline
\end{tabular}

Tabela 01: Ações e Propostas de Intervenções do Maciço Residual de Uruburetama, CE.

Fonte: NASCIMENTO NETO, Jose Nelson. (2016).

Diante das características naturais e sociais da área associada a uma série de etapas almejamos a possibilidade de atingir um cuidado do ambiente ao considerar a participação da sociedade no processo de conservação dos recursos naturais ao passo que sua exploração gera a descaracterização da paisagem e em virtude do desenvolvimento econômicos dos municípios devese considerar a preservação da natureza.

\section{CONSIDERAÇÕES FINAIS}

Diante do contexto, constatamos que a fisionomia das vertentes é alterada em consequência do uso do setor primário e que ao longo das décadas subsequente esse processo vem sendo agravado, em virtude que os demais setores econômicos que influenciam a descaracterização da natureza se dar em razão da configuração da superfície terrestre.

Contudo, acreditamos que as atividades econômicas devem ser planejadas a nível municipal levando em consideração a diversidade dos elementos da natureza que configuram a dinâmica da paisagem, ao passo que as mesmas necessitam de um planejamento ambiental local em face de realidade da pesquisa.

\section{REFERÊNCIAS}

AB'SABER, Aziz. Os Domínios de Natureza no Brasil: Potencialidades Paisagísticas. São Paulo, Ateliê Editorial, 2003.

BERTRAND, G. Paisagem e Geografia Física Global Esboço Metodológico. R. RA`E GA, Editora UFPR, n. 8, p. 141-152. Curitiba: 2004.

COLANGELO, A. C.. Movimentos de massa e evolução geomorfológica das vertentes no alto vale do paraíba do sul - são luis do paraitinga-sp. Tese de doutorado apresentado ao Departamento de Geografia da USP, 1995. 
CEARÀ. Perfil Básico Municipal 2012 Itapajé. Disponível em: http://www.ipece.ce.gov.br/publicacoes/perfil_basico/pbm-2012/Itapaje.pdf>: Acessado em: 12. Maio de 2014.

Disponível em: <http://www.ipece.ce.gov.br/publicacoes/perfil_basico/pbm2012/Uruburetama.pdf > Acessado em: 12 Maio de 2014.

Maio de 2014.

. Disponível em: <http://www.itapipoca.ce.gov.br/files/pbm_2012.pdf.> Acessado em 12.

2012/Iraucuba.pdf. $>$

Disponível em: <http://www.ipece.ce.gov.br/publicacoes/perfil_basico/pbmAcessado em 12. Maio de 2014.

Disponível em: <http://www.ipece.ce.gov.br/publicacoes/perfil_basico/pbm2012/Umirim.pdf> Acessado em 12. Maio de 2014.

FALCÃO SOBRIHO, J. Relevo e Paisagem: Proposta Metodológica. Sobral. Editora Sobral Gráfica, 2007. OLIVEIRA, V. P. e CARRASCO, C. G. Sectorialización Jierarquizada de Paisajens: Elejemplo de La Sierra de Uruburetama En El Semiarido Brasileiro (Ceará-Brasil). Mercator. Revista de Geografia da UFC. Ano 02, número 03. Fortaleza: 2003.

ROSS, J. L. S.. O Registro Cartográfico dos Fatos Geomórficos e a Questão da Taxonomia do Relevo. Revista do Departamento de Geografia, v, 6, 1992.

RIBEIRO, A. G.. Paisagem e Organização Espacial na Região de Palmas e Guarapuava. /Tese de Doutorado apresentado ao Departamento de Geografia da USP, 1989.

SILVA, M. V. C.. Análise geoambiental: subsídios do planejamento agrícola da serra de Uruburetama-Ce. Dissertação de Mestrado apresentado ao Programa de Pós Graduação em Geografia da Universidade Estadual do Ceará, UECE. Fortaleza, 2007.

\section{AGRADECIMENTOS}

Ao Programa de Pós-Graduação/Mestrado Acadêmico em Geografia-MAG/UVA.

A FUNCAP.

Recebido em: 14/08/2016

Aceito para publicação em: 01/10/2016 